\title{
Morphology and physiology of anaerobic granular sludge exposed to an organic solvent
}

\author{
J.C. Costa, I. Moita, E.C. Ferreira, M.M. Alves* \\ IBB - Institute for Biotechnology and Bioengineering, Centre of Biological Engineering, University of Minho, 4710-057 Braga, Portugal
}

\section{A R T I C L E I N F O}

\section{Article history:}

Received 7 July 2008

Received in revised form

25 November 2008

Accepted 31 December 2008

Available online 9 January 2009

\section{Keywords:}

Anaerobic granular sludge

Methanogenic activity

Quantitative image analysis

Toxic shock load

Solvent

\begin{abstract}
A B S T R A C T
The use of quantitative image analysis techniques, together with physiological information might be used to monitor and detect operational problems in advance to reactor performance failure. Industrial organic solvents, such as White Spirit, are potentially harmful to granular sludge. In preliminary batch assays, $33 \mathrm{mg} \mathrm{L}^{-1}$ of solvent caused $50 \%$ relative biomass activity loss. In an expanded granular sludge blanket reactor fed with $40 \mathrm{mg} \mathrm{L}^{-1}$ of solvent, during $222 \mathrm{~h}$, the reactor performance seemed to be unaffected, presenting COD removal efficiency consistently $>95 \%$. However, in the last days of exposure, the biogas production and the methane content were inhibited. Afterwards, already during recovery phase, the COD removal efficiency decreased to $33 \%$, probably because the reactor was underloaded and the biomass became saturated in solvent only at this stage. In the first hours of exposure the specific acetoclastic and the specific hydrogenotrophic methanogenic activities decreased $29 \%$ and $21 \%$, respectively. The $\%$ of aggregates projected area with equivalent diameter $\left(D_{\text {eq }}\right)>1 \mathrm{~mm}$ decreased from $81 \%$ to $53 \%$. The mean $D_{\text {eq }}$ of the aggregates $\geq 0.2 \mathrm{~mm}$ decreased, as well as the settling velocity, showing that the granules experienced fragmentation phenomenon caused by the solvent shock load. The ratio between total filaments length and total aggregates projected area (LfA) increased 2 days before effluent volatile suspended solids, suggesting that LfA could be an early-warning indicator of washout events.
\end{abstract}

(c) 2009 Elsevier B.V. All rights reserved.

\section{Introduction}

Organic solvents comprise a group of various liquid hydrocarbons obtained from the intermediate products of crude distillation. They are used in the chemical industry as solvent for extraction, cleaning, and degreasing, and, in aerosols, paints, wood preservatives, lacquers, varnishes, and asphalt products. The destiny of petroleum type pollutants in the environment has been investigated in many studies [1]. Also, the biodegradation of many components of petroleum hydrocarbons has been reported in a variety of terrestrial and marine ecosystems [2]. Organic solvents are flammable, malodorous and potentially toxic to aquatic organisms and thus require complete elimination by wastewater treatment systems [3]. Due to the hydrophobic nature of hydrocarbons they are mostly bound to the sludge and escape aerobic treatment in a wastewater treatment plant making them present in the anaerobic post treatment [4,5]. It is nowadays undeniable that various toxic organic compounds, such as surfactants and hydrocarbons, like the organic solvent White Spirit [6] are found in sewage and industrial wastewaters. A review of the toxicology of mineral spirits, expanding the existing database on the toxicology of this

\footnotetext{
* Corresponding author. Tel.: +351 253 604400; fax: +351 253678986 .

E-mail address: madalena.alves@deb.uminho.pt (M.M. Alves).
}

group of hydrocarbon solvents can be found in [7]. Wastewater containing solvents poses a risk to biological treatment systems [8], with emphasis in anaerobic digesters because of their high biomass adsorption capability.

Less than 20 years ago it was a generally accepted idea that hydrocarbons, except for comparably reactive ones such as acetylene, could not be degraded in the absence of molecular oxygen [9]. Meanwhile, studies have reported about the degradation of hydrocarbons in anaerobic systems. Spormann and Widdel [10] present a review focused on the anaerobic degradation of aromatic and saturated hydrocarbons. An anaerobic completely stirred tank reactor fed with pharmaceutical wastewater, experienced a dramatic deterioration in performance in terms of chemical oxygen demand (COD) removal efficiency (almost none) and acetoclastic methanogenic activity (less than $10 \mathrm{mLCH}_{4}$ gTVS $^{-1} \mathrm{~d}^{-1}$ ) and a significant increase in volatile fatty acids (VFA) concentration [11]. Enright et al. [12] used expanded granular sludge bed reactors for the treatment of solvent contaminated wastewater at $15^{\circ} \mathrm{C}$, and achieved COD removal efficiencies of $60-70 \%$. However, despite current knowledge about the anaerobic digestion process little is known about the effects caused by solvents in anaerobic granular sludge.

Combination of accurate morphological parameters, given by quantitative image analysis at micro- and macro-structure levels, with physiological activity of anaerobic granular sludge and 
reactor performance, may provide pertinent information about the stability of high rate anaerobic reactors in the presence of potential disturbances. The usefulness of this methodology in the detection of operational problems was already demonstrated for anaerobic granular sludge in contact with detergent/surfactant [13]. Like surfactants, solvents can disrupt the efficient functionality of anaerobic digesters when a redundant failure occurs because of its widespread use in industry. This work focuses on the study of effects caused by the exposure of anaerobic granular sludge to the organic solvent White Spirit, which is the most widely used solvent in the paint industry.

\section{Methods}

\subsection{Solvent characterization}

The solvent tested is a paraffin-derived transparent liquid, which is a common organic solvent used in extraction, cleaning and degreasing industrial processes. It is a mixture of saturated aliphatic and alicyclic $\mathrm{C} 7$ to $\mathrm{C} 12$ hydrocarbons with a maximum content of $25 \%$ of $\mathrm{C} 7$ to $\mathrm{C} 12$ alkyl aromatic hydrocarbons. The solvent presents a density $\left(15^{\circ} \mathrm{C}\right)$ of about $785 \mathrm{~kg} \mathrm{~m}^{-3}$.

\subsection{Toxicity assays}

The effect of an inhibitor in the methanogenic activity of a specific trophic group may be determined following the increase of biogas, in sealed vials.

After biomass acclimation at $37^{\circ} \mathrm{C}$ and $150 \mathrm{rpm}$, toxicity batch experiments were performed by adding sodium acetate $(30 \mathrm{mM})$ and increasing solvent concentrations $(1.6,7.9,39.3$, and $78.5 \mathrm{mg} \mathrm{L}^{-1}$ ) to the sludge, in batch vials. Working volume was $12.5 \mathrm{~mL}$, and total volume was $25 \mathrm{~mL}$. Fifty percent inhibition concentration $\left(\mathrm{IC}_{50}\right)$ was defined as the solvent concentration that caused $50 \%$ relative acetoclastic activity loss. All batch experiments were performed in triplicate assays.

\subsection{Experimental set-up}

A Plexiglas expanded granular sludge blanket(EGSB) reactor was used. The reactor had a height of $1.95 \mathrm{~m}$ and internal diameter of $21 \mathrm{~mm}$. The working volume was $1.15 \mathrm{~L}$ and the up-flow velocity was $4.0 \mathrm{~m} \mathrm{~h}^{-1}$. Temperature was kept at $37 \pm 1^{\circ} \mathrm{C}$ by means of an external jacket for water circulation.

\subsection{Inoculum and substrate}

The EGSB reactor was inoculated with $400 \mathrm{~mL}$ of granular sludge. The biomass was characterized in terms of specific methanogenic activity (SMA) with sodium acetate (212 \pm $\left.27 \mathrm{mLCH}_{4 @ S T P} \mathrm{gVSS}^{-1} \mathrm{~d}^{-1}\right)$ and $\mathrm{H}_{2} / \mathrm{CO}_{2} \quad\left(910 \pm 85 \mathrm{mLCH}_{4 @ S T P}\right.$ $\mathrm{gVSS}^{-1} \mathrm{~d}^{-1}$ ) as substrates. The morphological characteristics assessed by quantitative image analysis were: filaments length/ total area of aggregates, LfA $=24 \mathrm{~mm}^{-1}$; total filament length/ volatile suspended solids $=1800 \mathrm{mgVSS}^{-1}$; volatile suspended solids/total projected area $=13 \mathrm{~g} \mathrm{~m}^{-2}$. The volatile suspended solids (VSS) were $26.5 \mathrm{~g} \mathrm{~L}^{-1}$ and settling velocity was $26 \pm 14 \mathrm{~m} \mathrm{~h}^{-1}$.

The reactors were fed with $1.5 \mathrm{gCOD} \mathrm{L}^{-1}$ of ethanol. Sodium bicarbonate was added as the alkalinity source $\left(2 \mathrm{~g} \mathrm{~L}^{-1}\right)$. Micro- and macro-nutrients were added [14].

When the reactor was operating in steady-state, with stable values, either in terms of COD removal efficiency, SMA or morphological parameters, the solvent $\left(40 \mathrm{mg} \mathrm{L}^{-1}\right.$ ) was mixed with the feeding, with constant agitation, during $222 \mathrm{~h}$. The recovery phase was followed through 7 days.

\subsection{Routine analysis}

The COD and VSS were determined according to Standard Methods [15]. Biogas flow rate was measured by a Ritter Milligascounter (Dr. Ing. Ritter Apparatebau GmbH, Bochum, Germany). Methane content of biogas was determined by gas chromatography using a Porapack Q (100-180 mesh) column, with helium as the carrier gas at $30 \mathrm{~mL} \mathrm{~min}^{-1}$ and thermal conductivity detector. Temperatures of the detector, injector, and oven were 110,110 , and $35^{\circ} \mathrm{C}$, respectively. VFA and ethanol were determined by high performance liquid chromatography using an HPLC (Jasco, Japan) with a Chrompack column $(6.5 \mathrm{~mm} \times 30 \mathrm{~mm})$; sulfuric acid $(0.01 \mathrm{~N})$ at a flow rate of $0.7 \mathrm{~mL} \mathrm{~min}^{-1}$ was used as mobile phase. Column temperature was set at $60^{\circ} \mathrm{C}$. Detection of VFA and ethanol was made sequentially with an UV detector at $210 \mathrm{~nm}$ and a RI detector, respectively.

\subsection{Biomass sampling}

One of the most critical steps in this methodology is the sludge sampling. A sampling device was used to take biomass from the reactor without disturbing its morphology [16]. It was introduced at the top of the reactor and biomass was collected to the tube, along the reactor to get homogeneous and representative sample, avoiding mechanical stress. All the sludge samples were characterized by image analysis, SMA assays, settling velocity, and VSS content.

\subsection{Specific methanogenic activity assays}

The SMA tests were performed using a pressure transducer technique [17]. The specific acetoclastic activity (SAA) was measured in the presence of sodium acetate $(30 \mathrm{mM})$, and the specific hydrogenotrophic methanogenic activity (SHMA) was measured in the presence of $\mathrm{H}_{2} / \mathrm{CO}_{2} 80: 20(\mathrm{v} / \mathrm{v})$, at 1 bar. No trace-nutrients were added. Methane was measured by gas chromatography with helium as the carrier gas and a TCD detector.

\subsection{Biomass dilution}

Biomass samples must be diluted for image analysis using an optimized dilution factor. When the dilution is excessive the observer may unconsciously search objects over estimating them. If the dilution is insufficient, the objects will be overlaid. The optimal dilution value was determined as the lowest dilution that enabled the maximum percentage of objects to be recognized. The percentage of recognition is the ratio between the area of objects that are completely inside the image and the total area of objects in the image including those that are at the boundaries and cannot be completely recognized. In these experiments, the optimal dilution was 1:5.

\subsection{Image acquisition, processing, and analysis}

For the acquisition of filaments and micro-aggregates (equivalent diameter $\left(D_{\text {eq }}\right)<0.2 \mathrm{~mm}$ ) images, a volume of $35 \mu \mathrm{L}$ from the diluted sample was distributed on a slide and covered with a $20 \mathrm{~mm} \times 20 \mathrm{~mm}$ cover slip for visualization and image acquisition. This volume was exactly covered by the cover slip. Each image corresponded to a volume of $0.0445 \mu \mathrm{L}$. Then, more than 120 images were acquired. Image acquisition was obtained by dividing the cover slip into 42 identical fields and taking a photo in each imaginary square. At least three slides were examined to minimize sampling errors. Concerning to macro-aggregates $\left(D_{\mathrm{eq}} \geq 0.2 \mathrm{~mm}\right)$ images, an arbitrary volume was transferred to a Petri dish for visualization and image acquisition. All the aggregates present in that 
volume were captured. A minimum of 120 images were captured. Then, the VSS content in the Petri dish was measured.

Images used to quantify filaments and micro-aggregates were acquired through phase contrast and bright field, respectively, on a Nikon Diaphot 300 microscope (Nikon Corporation, Tokyo, Japan) with $100 \times$ magnification. Images used to quantify macroaggregates were acquired through visualization on an Olympus SZ 40 stereo microscope (Olympus, Tokyo, Japan) with $15 \times$ magnification. All the images were digitized and saved with the help of a CCD AVC D5CE Sony grey scale video camera (Sony, Tokyo, Japan) and a DT 3155 Data Translation frame grabber (Data Translation, Marlboro, Massachusetts) with $768 \times 576$ pixel size in 8 bits (256 grey levels) by Image Pro Plus (Media Cybernetics, Silver Spring, MD) software package.

Image processing and analysis was accomplished by means of three programmes developed in Matlab (The Mathworks, Inc., Natick, MA), for filaments, micro, and macro-aggregates. Descriptions of the programs can be found in [18].

\subsubsection{Morphological parameters}

The filaments length $(L)$ was determined by

$L=N \times 1.122 \times F_{\text {cal }}$

where $N$ is the number of pixels of the skeletonized filament, and $F_{\text {cal }}$ is the calibration factor ( $\mu \mathrm{m} /$ pixel) obtained using a micrometer. The factor 1.122 is used in order to homogenize the different angles of the filaments [19].

The specific total filament length $\left(L_{\text {spec }}\right)$ was calculated as

$L_{\text {spec }}=L / V_{\text {field }}$

where $V_{\text {field }}$ is the volume (in $\mu \mathrm{m}^{3}$ ) corresponding to the field of view (i.e. the image).

Relatively to aggregates programmes the following parameters were determined.

The total area $(T A)$ is given by the cumulative area of all aggregates, including the ones cut off by the boundaries:

$T A=\sum\left(N_{\text {obj }} \times F_{\text {cal }}\right)$

where $N_{\text {obj }}$ is the pixel sum of each object.

The aggregate area is given and allows determining the $D_{\text {eq }}$ by

$D_{\text {eq }}=2 \times \sqrt{(\text { Area } / \pi)}$ by

The specific area occupied by the aggregates $\left(A_{\mathrm{spec}}\right)$ is calculated

$A_{\text {spec }}=T A / V_{\text {field }}$

Finally, morphological parameters representing the dynamic evolution of filaments and aggregates inside the reactor were calculated as the ratios: total filaments length per VSS (TL/VSS), and, VSS per total aggregates area (VSS/TA), respectively. Where VSS represents the volatile suspended solids present in each sample.

A morphological parameter based on the ratio of specific total filament length to total aggregates projected area is determined by:

$\mathrm{LfA}=L_{\text {spec }} /\left(A_{\text {spec }}<0.2 \mathrm{~mm}+A_{\text {spec }} \geq 0.2 \mathrm{~mm}\right)$

where $A_{\text {spec }}<0.2 \mathrm{~mm}$ and $A_{\text {spec }} \geq 0.2 \mathrm{~mm}$ are the specific aggregate area ratio for aggregates of equivalent diameter $<$ and $\geq 0.2 \mathrm{~mm}$, respectively.

\subsection{Settling velocity}

The settling velocity was measured by depositing several biomass samples in the top of a column filled with water. Afterwards, the time that each particle takes to cover the column $320 \mathrm{~mm}$ was measured using a chronometer that automatically registers the time for each particle in an Excel spreadsheet. Then, the average of all individual sedimentation velocities was determined. More than 150 particles were considered in the calculation.

\section{Results and discussion}

\subsection{Toxicity test}

Previously to exposure in a lab-scale reactor, a series of batch assays was performed to determine the concentration of solvent that caused $50 \%$ relative activity loss. The specific acetoclastic activity decreased proportionally to the solvent concentration increase. The $\mathrm{IC}_{50}$ was $33 \mathrm{mg} \mathrm{L}^{-1}$.

\subsection{Reactor performance}

The EGSB reactor fed with $4.8 \mathrm{kgCOD} \mathrm{m}^{-3} \mathrm{~d}^{-1}$ and hydraulic retention time of $8 \mathrm{~h}$, achieved COD removal efficiency $>95 \%$. When the reactor showed stable performance was exposed to $40 \mathrm{mg} \mathrm{L}^{-1}$ of solvent. In the exposure phase the organic loading rate (OLR) increased to $6 \mathrm{kgCOD} \mathrm{m}^{-3} \mathrm{~d}^{-1}$ (Fig. 1). The reactor performance seemed to be unaffected by the shock load. The COD removal efficiency remained constantly above $95 \%$. However, during the last two days of exposure, the biogas production and methane content decreased to residual values (data not shown).

In the first 3 days of recovery phase, the COD removal efficiency decreased, reaching a minimum of 33\% (Fig. 1). Simultaneously, the effluent volatile fatty acids increased, in particular acetate with concentrations of $500 \mathrm{mgCOD} \mathrm{L}^{-1}$ (data not shown). Several possible explanations can justify this later decrease of the COD removal efficiency: (a) Urra et al. [20] studied the influence of the biomass concentration in the level of inhibition and the anaerobic degradation kinetics resulting from the incorporation of toxic compounds (long chain fatty acids, polycyclic aromatic hydrocarbons, linear alkylbenzene sulphonates and organic acids) in an anaerobic system. They observed a link between the tolerance to toxic compounds and the biomass concentration. In addition, it was observed that the degradation kinetics is affected, whether diminishing the methane production (polycyclic aromatic hydrocarbons, linear alkylbenzene sulphonates, organics acids) or increasing the initial latency time (long chain fatty acids). In the present study, once the OLR was too small for an EGSB reactor, i.e. the reactor was underloaded, the negative effects on the reactor performance were postponed, because there was enough biomass to degrade the ethanol. (b) In the batch assays $\left(\mathrm{IC}_{50}=33 \mathrm{mg}_{\text {solvent }} \mathrm{d}^{-1}\right.$ ) the solvent was in direct and constant contact with the biomass, however,

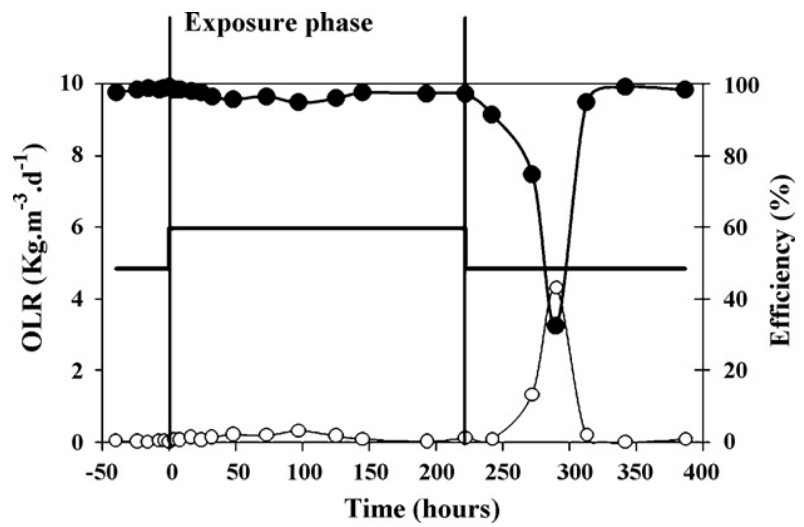

Fig. 1. Time course of: influent organic loading rate (-), effluent organic loading rate $(\bigcirc)$, and, COD removal efficiency $(\bullet)$. 

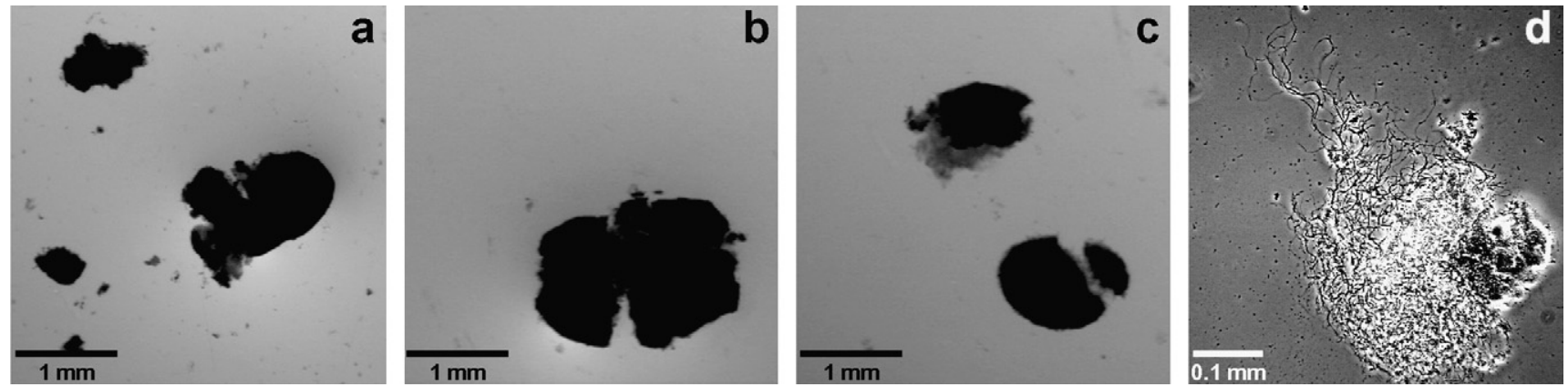

Fig. 2. Images of granules fragmentation and filaments release during exposure to solvent.

in continuous operation the contact was not so intensive. During the reactor operation, the solvent accumulation in a top layer of the reactor was observed. The solvent short-circuited through the reactor, possibly because of its small density, causing a temporary shift in the concentration in direct and constant contact with the biomass. This concentration is smaller than the effectively fed. Afterwards, this top layer was recirculated causing a punctual increase of the solvent concentration entering in the reactor. This higher concentration might be responsible for the reactor performance decrease. (c) As stated before hydrocarbons have the tendency to bind onto biomass [5]. The granular sludge was $222 \mathrm{~h}$ exposed to solvents. These caused its saturation with consequent granules fragmentation (Figs. 2 and 3c) and biomass washout (Fig. 3a). Since the biogas production and methane content decreased, while acetate concentration increased, and the ethanol concentration remained undetected in the effluent, is clear that the methanogenesis was inhibited. It is possible to speculate that the Methanosaeta genera, which is a very slow growing archaea could have been selectively washed out, as already observed during organic loading disturbances [21].

Ninety hours after shock load was stopped, the reactor recovered previous COD removal efficiencies of $>95 \%$ (Fig. 1). The biogas flow and the methane content also increased to values close the initial ones (data not shown). Once the shock load was already stopped when the negative effects became visible, the reactor was capable of recover. According to [20], if the testing period is not enough, there is the risk of not fully developing the degradation kinetics causing us to assume erroneous inhibition values. In this study, the exposure time was not enough to cause an irreversible inhibition in the biomass. It is possible to conclude that the EGSB reactor is capable of resist to a punctual contamination with a small concentration of solvent. However, if the exposure time or the solvent concentration is high is probable that the reactor performance will decrease drastically.

\subsection{Specific methanogenic activity}

The effects on the SMA were not significant as could be expected after the batch assays results. Nonetheless, during the first $24 \mathrm{~h}$ of exposure, the solvent shock load caused 21\%decrease in the SHMA (Fig. 4). As for the SAA, a continuous decrease was observed during the first $73 \mathrm{~h}$ of shock load, with $29 \%$ of inhibition (Fig. 4). The acetoclastic bacteria, which were protected inside the granules, became more vulnerable to the solvent effects, because of granule
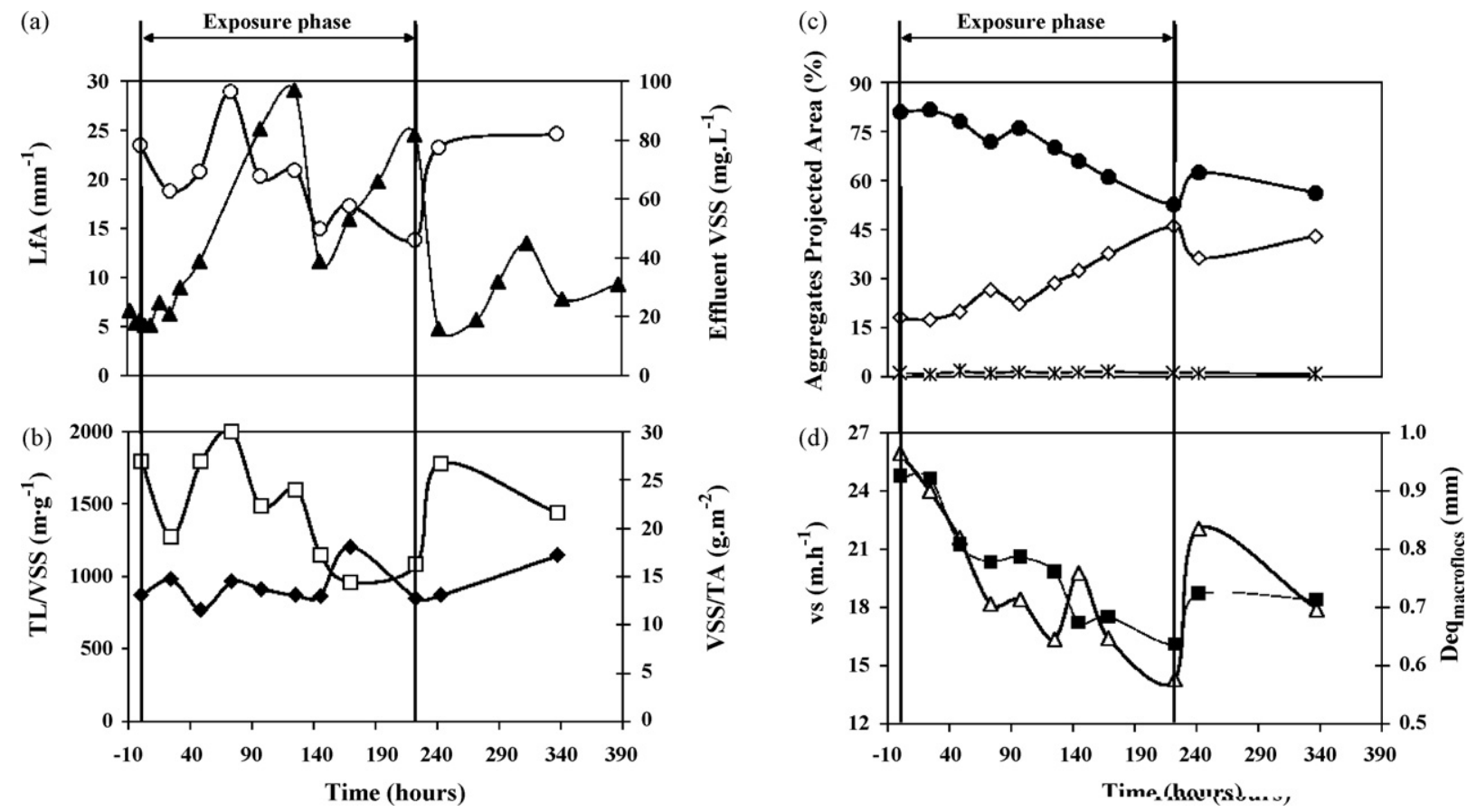

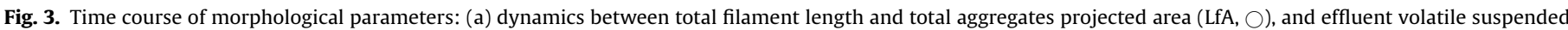

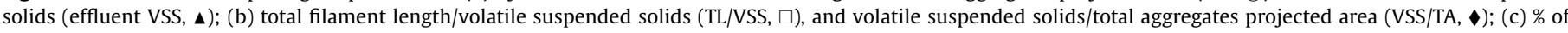

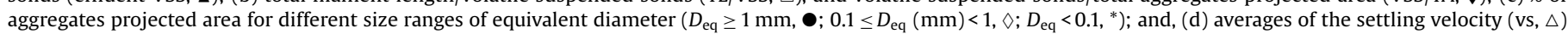
and the macroflocs equivalent diameter $\left(D_{\text {eqmacroflocs }}, \mathbf{\square}\right)$. 


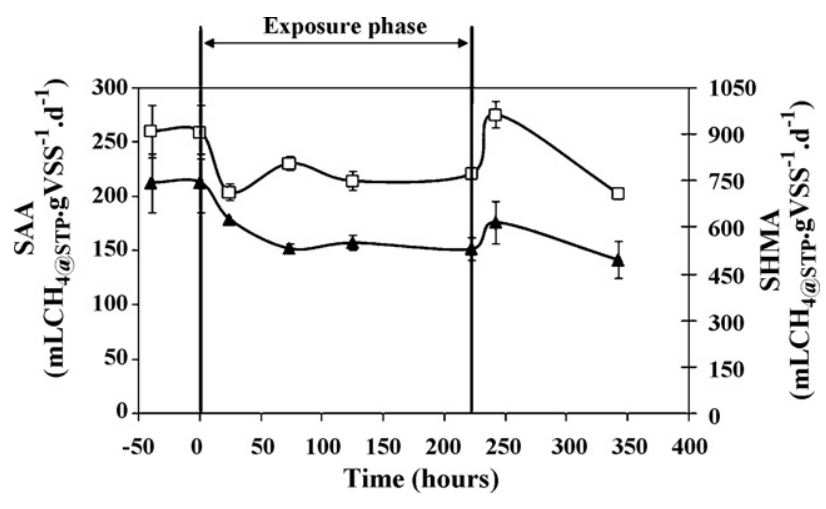

Fig. 4. Time course of specific acetoclastic activity (SAA, \), and, specific hydrogenotrophic methanogenic activity (SHMA, $\square$ ).

disintegration (Figs. 2 and 3c). Subsequently the SHMA and the SAA stabilised around 760 and $150 \mathrm{mLCH}_{4 @ S T P} \mathrm{gVSS}^{-1} \mathrm{~d}^{-1}$, respectively, until the end of the exposure phase.

During the recovery phase, a sudden increase in the SMA was observed (Fig. 4). This observation was unexpected because during the same period the reactor performance decreased. It is possible that the granules fragmentation facilitate the transport of the substrate to the bacteria inside the granules causing a momentary increase of the SMA. The SMA increases with the decrease of mass transfer limitations between the bulk and the cores of the newly formed small particles after fragmentation was already stated in [16].

\subsection{Image analysis}

The main effect caused by the shock load was the granules fragmentation. Fig. 2 shows several granules breaking, with resulting decrease in size and release of filaments.

The \% of aggregates projected area with $D_{\mathrm{eq}} \geq 1 \mathrm{~mm}$ decreased from $81 \%$ to $53 \%$ during the exposure phase, and the \% of projected area of small aggregates $\left(0.1 \leq D_{\text {eq }}(\mathrm{mm})<1\right)$ increased from $18 \%$ to $46 \%$ (Fig. $4 \mathrm{c}$ ). The mean macroflocs $D_{\text {eq }}$ decreased consistently from 0.9 to $0.6 \mathrm{~mm}$ (Fig. $4 \mathrm{~d}$ ). Fig. 5 shows granules original and respective binary images, from the inoculum, at the middle of operation $(t=125 \mathrm{~h})$, and at the end of exposure, supporting the previous measurements. Thus, the decrease in granules size is clearly observed. The constant binding of hydrocarbons to cell membranes caused severe damages, and can explain the aggregates fragmentation/erosion with a consequent decrease of $D_{\text {eq }}$ and filaments release. The morphological parameters $D_{\mathrm{eq}} \geq 1$ and $0.1 \leq D_{\mathrm{eq}}<1$, were the variables with higher influence to recognize a solvent shock load using a principal component analysis [22]. Thus, although the reactor performance deteriorates only in the last hours of the exposure phase, a change in the macrostructure of granules was immediately observed when the shock load was applied. This emphasizes the value of monitoring the granular sludge morphology to detect possible operational problems caused by toxic compounds.

During the first hours of exposure the TL/VSS decreased, possibly because of the free filaments washout. After that, as a consequence of granules fragmentation/erosion the filaments release from the granules occurred, as observed in the TL/VSS increase from 1300 to $2000 \mathrm{~m} \mathrm{~g}^{-1} 40 \mathrm{~h}$ after the exposure (Fig. 3b). However, during this phase the biggest part of filaments are still connected to the granules (protruding filaments) as can be observed in Fig. 2d. During this stage the highest increase in LfA parameter occurs (Fig. 3a). Later, when the filaments are completely free in the bulk, the washout takes place, corresponding to the highest peak of effluent VSS (Fig. 4a). Consequently, the LfA and TL/VSS decreased to $1100 \mathrm{~m} \mathrm{~g}^{-1}$ and $14 \mathrm{~mm}^{-1}$, respectively.

The LfA parameter was able to be an early-warning indicator of washout events during the solvent shock load, as also suggested in other toxic shock loads $[13,23]$. During this experiment the LfA increased $35 \%$ between hours 24 and 73 (Fig. 3a), reaching the value of $29 \mathrm{~mm}^{-1}$. In the same figure is showed that the effluent VSS only achieved its maximum value at $125 \mathrm{~h}$, i.e. $52 \mathrm{~h}$ after LfA.

At the end of exposure phase, $145 \mathrm{~h}$ after the effluent VSS decreased, it was observed a new peak of $82 \mathrm{mg} \mathrm{L}^{-1}$, suggesting a washout of small aggregates. This hypothesis was enhanced by the $\%$ of aggregates projected area with $D_{\text {eq }} \geq 1 \mathrm{~mm}$ increase during the first hours of recovery phase (Fig. 3c).

A decrease in the mean settling velocity from 26 to $14 \mathrm{~m} \mathrm{~h}^{-1}$ was observed during exposure phase (Fig. 3d). However, the apparent granules density (VSS/TA) was almost constant, around $13 \mathrm{~g} \mathrm{~m}^{-2}$ (Fig. 3b). Therefore, the granules fragmentation/erosion may have caused the settling velocity decrease, as observed by the similar trends of the averages of settling velocity and macroflocs $D_{\text {eq }}$ (Fig. 3d). Figs. 2 and 5 show that the granules became more irregular and less robust potentially contributing to the settling velocity decrease.
Inoculum
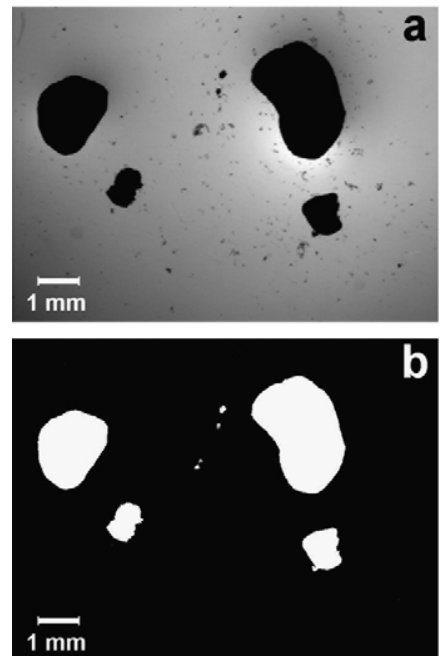

time $=125 \mathrm{~h}$
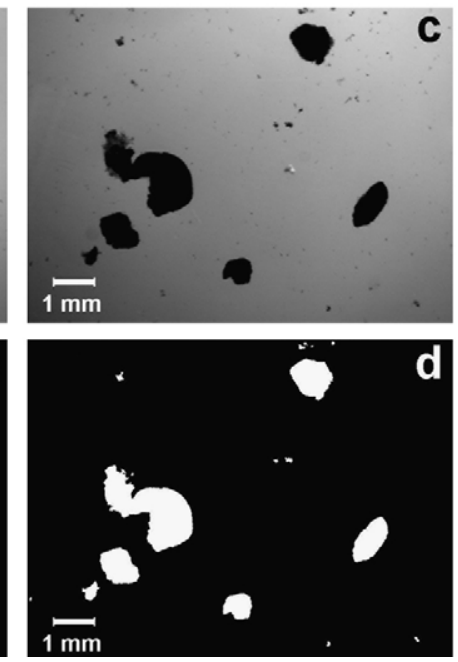

time $=\mathbf{2 2 2} \mathrm{h}$
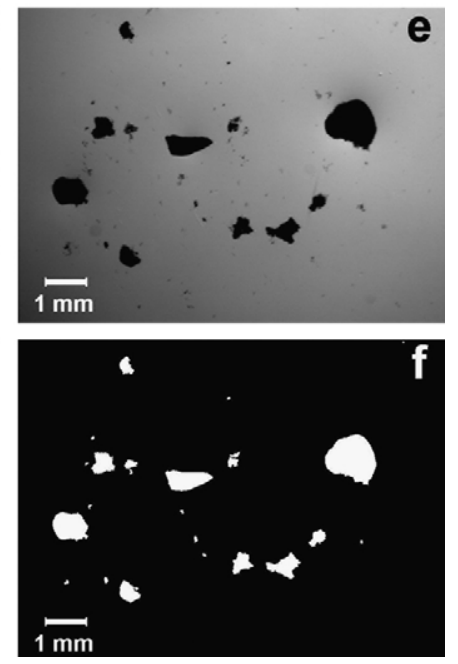

Fig. 5. Original (a, c, e) and binary (b, d, f) images of granules from the inoculum, after $125 \mathrm{~h}$ of exposure, and at the end of shock load ( $222 \mathrm{~h}$ ). 


\section{Conclusions}

In batch assays it was determined that $33 \mathrm{mg} \mathrm{L}^{-1}$ of solvent caused 50\% loss of specific acetoclastic activity. Nonetheless, the overall reactor performance was unaffected by a White Spirit shock load of 9 days at $40 \mathrm{mg} \mathrm{L}^{-1}$. The COD removal efficiency was consistently $>95 \%$ during the exposure phase, probably because the reactor was underloaded and the negative effects were postponed. However, in the last days of exposure a decrease in biogas production and methane content was observed. During the recovery phase the efficiency decreased to $33 \%$, possibly due to the accumulation and saturation of solvent onto the biomass or the temporary increase in solvent concentration. However, the reactor rapidly recovered its high efficiency, indicating a temporary inhibition. A decrease of $21 \%$ was observed in the SHMA whereas the SAA decreased $29 \%$ a few hours after initial exposure.

Phenomenon of granular erosion and/or fragmentation and filaments release were identified and quantified during the exposure of anaerobic granular sludge to an organic solvent. The \% of aggregates projected area with $D_{\text {eq }} \geq 1 \mathrm{~mm}$ decreased from $81 \%$ to $53 \%$. The average settling velocity decreased from 26 to $14 \mathrm{~m} \mathrm{~h}^{-1}$, although the VSS/TA was almost constant through the exposure phase, symptomatic that the granules density remained approximately unchanged. The decrease in settling velocity was mainly caused by the decrease in size as a result of granules erosion/fragmentation. The peak in effluent VSS was observed $52 \mathrm{~h}$ after LfA increased $35 \%$, suggesting that it could be used as an early-warning indicator of washout events when anaerobic granular sludge is exposed to organic solvents such as White Spirit.

\section{Acknowledgements}

We grateful acknowledge the financial support to J.C. Costa and I. Moita through the grant SFRH/BD/13317/2003 and the project POCTI/AMB/60141/200, respectively, from the Fundação para a Ciência e a Tecnologia (Portugal).

\section{References}

[1] M.P. Antic, B.S. Jovancicevic, M. lic, M.M. Vrvic, J. Schwarzbauer, Petroleum pollutant degradation by surface water microorganisms, Environ. Sci. Pollut. Res. 13 (5) (2006) 320-327.

[2] R. Margesin, F. Schinner, Biodegradation and remediation of hydrocarbons in extreme environments, Appl. Microbiol. Biotechnol. 56 (5-6) (2001) 650-663.

[3] M.P. Henry, B.A. Donlon, P.N. Lens, E.M. Colleran, Use of anaerobic hybrid reactors for treatment of synthetic pharmaceutical wastewaters containing organic solvents, J. Chem. Technol. Biotechnol. 66 (3) (1996) 251-264.

[4] T.B. El-Hadj, J. Dosta, J. Mata-Álvarez, Biodegradation of PAH and DEHP micropollutants in mesophilic and thermophilic anaerobic sewage sludge digestion, Wat. Sci. Technol. 53 (8) (2006) 99-107.
[5] N. Christensen, D.J. Batstone, Z. He, I. Angelidaki, J.E. Schmidt, Removal of polycyclic aromatic hydrocarbons (PAHs) from sewage sludge by anaerobic degradation, Wat. Sci. Technol. 50 (9) (2004) 237-244.

[6] T. McGovern, T.F. Guerin, S. Horner, B. Davey, Design, construction and operation of a funnel and gate in-situ permeable reactive barrier for remediation of petroleum hydrocarbons in groundwater., Water Air Soil Pollut. 136 (1-4) (2002) 11-31.

[7] M.A. Amoruso, J.F. Gamble, R.H. Mckee, A.M. Rohde, A. Jaques, Review of the toxicology of mineral spirits, Int. J. Toxicol. 27 (1) (2008) 97-165.

[8] B.C. Inanc, K. Alp, F. Ciner, B. Mertoglu, I. Ozturk, Toxicity assessment on combined biological treatment of pharmaceutical industrial effluents, Wat. Sci. Technol. 45 (12) (2002) 135-142.

[9] B. Schink, Anaerobic digestion: concepts, limits and perspectives, Wat. Sci. Technol. 45 (10) (2002) 1-8.

[10] A.M. Spormann, F. Widdel, Metabolism of alkylbenzenes, alkanes, and other hydrocarbons in anaerobic bacteria, Biodegradation 11 (2000) 85-105.

[11] A.T. Akarsubasi, O. Ince, B. Kirdar, N.A. Oz, D. Orhon, T.P. Curtis, I.M. Head, B.K. Ince, Effect of wastewater composition on archaeal population diversity, Wat. Res. 39 (8) (2005) 1576-1584.

[12] A.-M. Enright, S. McHugh, G. Collins, V. O'Flaherty, Low-temperature anaerobic biological treatment of solvent-containing pharmaceutical wastewater, Wat. Res. 39 (19) (2005) 4587-4596.

[13] J.C. Costa, A.A. Abreu, E.C. Ferreira, M.M. Alves, Quantitative image analysis as a diagnostic tool for monitoring structural changes of anaerobic granular sludge during detergent shock loads, Biotechnol. Bioeng. 98 (1) (2007) 60-68.

[14] A.J.B. Zehnder, B.A. Huser, T.D. Brock, K. Wuhrmann, Characterization of an acetate-decarboxylating, non-hydrogen-oxidizing methane bacterium, Arch. Microbiol. 124 (1) (1980) 1-11.

[15] Standard Methods for the Examination of Water and Wastewater, 17th ed. American Public Health Association/American Water Works Association/Wate Environment Federation, Washington DC, USA, 1989.

[16] A.A. Abreu, J.C. Costa, P. Araya-Kroff, E.C. Ferreira, M.M. Alves, Quantitative image analysis as a diagnostic tool for identifying structural changes during a revival process of anaerobic granular sludge, Wat. Res. 41 (2007) 1473-1480.

[17] E. Colleran, F. Concannon, T. Goldem, F. Geoghegan, B. Crumlish, E. Killilea, M. Henry, J. Coates, Use of methanogenic activity tests to characterize anaerobic sludges, screen for anaerobic biodegradability and determine toxicity thresholds against individual anaerobic trophic groups and species, Wat. Sci. Technol. 25 (7) (1992) 31-40.

[18] A.L. Amaral, Image analysis in biotechnological processes: application to wastewater treatment. PhD thesis, University of Minho, Braga, Portugal, 2003 <http://hdl.handle.net/1822/4506>.

[19] A.E. Walsby, A. Avery, Measurement of filamentous cyanobacteria by image analysis, J. Microbiol. Meth. 26 (1996) 11-20.

[20] J. Urra, P. Poirrier, J. Segovia, Y. Lesty, R. Chamy, Analysis of the methodology to determine anaerobic toxicity: evaluation of main compounds present in wastewater treatment plants (WWTPs), Wat. Sci. Technol. 57 (6) (2008) 857-862.

[21] J.C. Costa, I. Moita, A.A. Abreu, E.C. Ferreira, M.M. Alves, Advanced monitoring of high rate anaerobic reactors through quantitative image analysis of granular sludge and multivariate statistical analysis, Biotechnol. Bioeng. 102 (2) (2009) 445-456.

[22] J.C. Costa, M.M. Alves, E.C. Ferreira, Principal component analysis and quantitative image analysis to predict effects of toxics in anaerobic granular sludge, Biores. Technol. 100 (3) (2009) 1180-1185.

[23] A.L. Amaral, M.A. Pereira, M. da Motta, M.-N. Pons, M. Mota, E.C. Ferreira, M.M Alves, Development of image analysis techniques as a tool to detect and quantify morphological changes in anaerobic sludge. II. Application to a granule deterioration process triggered by contact with oleic acid, Biotechnol. Bioeng. 87 (2) (2004) 194-199. 